\title{
Interview with Claudia Bokel, member of the International Olympic Committee
}

\author{
ARNO MÜLLER ${ }^{1}$
}

Claudia Bokel has been a member of the International Olympic Committee (IOC), one of the most powerful organisations in the world of sports, since 2008, becoming a member of the executive board in 2012. She has been Vice-Chair (2010-2012) and is now Chair (2012-) of the Athlete's Commission. She became a member of the Ethics Commission in 2011.

In her sports career as a fencer (epee) Claudia Bokel was highly successful, winning the world championship in 2001 (individual) and the silver medal at the Olympic Games in 2004 (team).

\section{What did you personally perceive as highlights of the London 2012 Olympics?}

Clearly, the enthusiasm of the spectators. An estimated 15 million people lined the streets for the Olympic Torch Relay through the UK, including 4.2 million in London alone. More than 7 million spectators visited venues in the first 10 days of the Games and 2.7 million spectators visited the Olympic Park. More than 5 million people attended Live Sites where events were displayed on big screens during the Olympics, with 110,000 people attending BT London Live in Hyde Park alone on Super Saturday.

Impressive figures! And what do you think has been problematic in the recent games? What do you think needs to be changed soon?

What I see as problematic at the recent games is that in many sporting disciplines older athletes - who still can perform at the top level - should be able to keep up a dual career (for example, pursuing sporting excellence, while also pursuing an education), but unfortunately these two do not always go hand-in-hand very well. It is not at all an easy job to do.

What do you think on the relationship between the Olympic Games and Paralympic Games? Did you think London 2012 gave a boost to the Paralympics (maybe fostered by the publicity around Oscar Pistorius)?

The Paralympics in London were a big success, all tickets were sold out long before the games. It's great to see such a success! The IOC is more than just a supporter of the Paralympic movement. For example, the president of the IPC Athlete Council is a member of the IOC Athletes Commission and vice versa. This is just one example of the close collaboration. 
In the media the name Pistorius often was connected with the term technodoping. In addition, the term gene doping has occasionally been read. What was your perception about doping in general at the Games in London?

The fight against doping is one of the top priorities for the IOC. London 2012 had the most extensive testing program in Olympic history. More than 5,000 tests were carried out, including tests of the top five in each event, as well as two tests by random selection. The samples will be kept for eight years, so that they can be examined again in the future, if new test tools for analyses become available. The question about technological doping in Paralympic sports is not an easy one - it is rather a question for experts. Oscar has been tested several times in the past and he was allowed to take part at the Olympic Games in London 2012. Really, it was great to see him there; he is an athlete who is a source of inspiration for others.

Technology and genetics are ambivalent. They can be used for good or for bad reasons. For example, on the one hand new (high-tech) prosthetic devices allow increased mobility and thus (possibly) a better quality of life. Another example is genomics ...

...probably there is a equilibrium, however you have to distinguish between "normal" life and the life of performance sports. Of course, gene doping is a major threat in real life and it is inexcusable to use genetic or technical manipulation to get an unfair advantage over opponents...

But what about genetic testing to detect, for example inherited heart diseases? Do you think those tests could be a reasonable addition to the standard preparticipation examinations for athletes?

Generally speaking, everything that can be done in order to protect health is important and good. The IOC medical commission, led by Arne Ljungqvist is very active in this field.

Are pre-participation screenings for performance athletes, especially genetic tests, currently on the agenda of the IOC, particularly the medical commission?

The IOC's Medical Commission observes very closely any kind of research that is related somehow to the health of athletes, including genetic testing. The IOC relies also on the findings of external experts.

Every now and then one can read about ethicists concerns about even genetic diagnosis. One criticism, for example, is that this diagnosis violates the athlete's autonomy to decide for him or herself. Maybe athletes do not want to know anything about their genetic make-up (good or bad). You're now also a member 
of the Ethics Commission at the IOC (congratulations!) - what's your view on the tension between the medical perspective and ethical criticism?

I would it leave it to the scientists to judge the existing diagnostic tools in the field of genetics. But, of course, it is important to consider and protect the athlete's privacy. This is often a thin line, especially in regard to doping. I believe that it is a question of proportionality.

In the debate on genetic diagnosis it is sometimes pointed out that genetic information is particularly sensitive. What do you think - should genetic information be judged differently from other types of medical information (e.g. ECGs)?

I believe that any personal information is sensitive.

On whom do you see the main responsibility resting in the context of preparticipation screenings (general or genetic)? Or let's put it like this: how about the responsibility of each athlete for his health? How about the responsibility of doctors, coaches/trainers, parents, sports organisations, governments?

I believe that the primary responsibility for the athlete's health is with the athlete himself. They are the ones who know their body best - and of course the entourage surrounding the athletes all the time, including family, trainer, doctor, etc. But sports and government officials should create the conditions to facilitate such pre-participation examinations - e.g. related to financing or feasibility of such tests.

How much decision-making power related to health/medical matters could, should, or must be in the hands of the athlete?

Personally, I think that the athletes themselves should be involved in all health and body related decisions. There is the strict liability rule in regard to doping, for example. Athletes need to know what medication they take. We know that this becomes a more and more sensitive issue the younger the athletes are. And we have to understand the importance of the aforementioned entourage.

These responsibilities are interrelated. Do you see any need for action, any need for clarification here?

If there is new evidence, and accordingly if new methods would be developed, then these issues need to be answered as the case arises.

What is it that, makes performance sport so special? And what is it that doctors (officials, and others) therefore should take into account in their daily work? 
One should never forget that you are dealing with people - it's not just about the health of the body. When both body and mind are in harmony, an important prerequisite for a peak performance is already given.

\section{What's the next big sporting event are you looking forward to?}

The next really big events to which I am already looking forward are the Winter Games in Sochi, as well as the Youth Olympic Games in Nanjing, both in 2014.

\section{"Do sports or stay healthy!" What do you think about that saying?}

Well, generalisations like that are certainly not good. We all know how sports can promote health, but we also know that sport - and above all performance sports - includes a risk of injury and you have to minimize that risk as much as possible. This is exactly the mission of the IOC Medical Commission.

Thank you very much for taking the time to do this interview.

My pleasure!

\footnotetext{
${ }^{1}$ Department of Philosophy of Sport and Sport History, University of Leipzig. arno.mueller@uni$\underline{\text { leipzig.de }}$
} 